\title{
Os sentidos das telenovelas nas trajetórias sociais de mulheres das classes populares ${ }^{1}$

\author{
Veneza Mayora Ronsini, Sandra Depexe, Gustavo Dhein, \\ Otávio Chagas Rosa e Hellen Barbiero
}

\section{Resumo}

0 foco do texto é entender os usos sociais da ficção televisiva por mulheres das frações baixa e média baixa das classes populares, em particular, a construção de uma feminilidade de classe, a qual é capturada pelas visões de mundo que as informantes manifestam. Tais representações se compõem de enunciados sobre as práticas cotidianas de gestão de si, do trabalho e do estudo, da família, das relações sociais e revelam a moral das mulheres. 0s métodos são a observação participante e 0 estudo de caso comparativo construído com base em perfis sociológicos individuais. Para a descrição e a interpretação dos mesmos, contamos com o auxílio do software de análise qualitativa NVIV09. 0s resultados indicam que as telenovelas oferecem às mulheres das classes populares promessas de transformação da vida amorosa, padrões de comportamento sexual, modos (respeitáveis) de apresentação no espaço público e 0 modelo do self ideal burguês.

\section{Palavras-Chave}

Telenovela. Classes populares. Feminilidade.

Veneza Mayora Ronsini । venezar@gmail.com Doutora em Sociologia pela Universidade de São Paulo - USP, Brasil. Pós-Doutora pela Nottingham Trent University, Inglaterra. Professora do Departamento de Comunicação Social da Universidade Federal de Santa Maria - UFSM, Brasil. Bolsista do CNPq.

Sandra Depexe I sandradpx@gmail.com Doutora em Comunicação Social e docente da Universidade Federal de Santa Maria - UFSM, Brasil.

Gustavo Dhein I gustavodhein@gmail.com Realiza doutorado em Comunicação Social com incentivo de bolsa CAPES na Universidade Federal de Santa Maria - UFSM, Brasil.

Otávio Chagas Rosa I otaviochagasr@hotmail.com Realiza mestrado em Comunicação Social na Universidade Federal de Santa Maria - UFSM, Brasil.

Hellen Barbiero I hellenbarbiero@gmail.com Realiza mestrado em Comunicação Social na Universidade Federal de Santa Maria - UFSM, Brasil.

\section{Introdução}

As telenovelas do horário nobre são parte dos processos ideológicos e culturais que reproduzem e modificam os laços sociais no Brasil, ao incitarem reflexões das pessoas comuns sobre a formação social brasileira e sobre temas como as desigualdades de classe e de gênero. 0 objetivo do presente texto ${ }^{2}$ é entender os usos sociais da ficção televisiva por mulheres das frações baixa e média baixa da classe trabalhadora e sua interferência na construção de uma feminilidade (modo de pensar, agir, sentir e valorar que são tidos como "femininos") de classe, capturada pelas visões de mundo que as informantes manifestam.

No artigo, discutimos a ritualidade (MartínBarbero, 2009), conceituada como o modo de ler 0 texto melodramático, a partir do exame da experiência de 12 mulheres jovens, maduras e idosas para compreender a construção de identidades femininas e suas relações com os modos de representar o gênero feminino. Concentramo-nos na descrição das representações da feminilidade, apresentando algumas indicações da origem familiar delas. Tais 
representações se compõem de enunciados sobre as práticas cotidianas de gestão de si e das relações sociais, os quais revelam a moral das mulheres de classe popular, isto é, um conjunto de imperativos, valores e critérios axiológicos que dão sentido às práticas e as constituem. A representação do papel da mulher é elaborada com sentimentos/emoções e definições de senso comum que se formam pela e na experiência de classe, caracterizada pela escassez de recursos econômicos e pelo acesso desigual aos bens culturais e que determinam as subjetividades (o que elas pensam que são como indivíduos) e a consciência das condições concretas de existência.

A mediação da ritualidade é restringida aos modos de interpretação do texto ficcional que ocorrem para além do momento de ver, em função de a metodologia estar centrada na construção de perfis sociológicos individuais e só incluir um protocolo parcial (observação participante com quatro mulheres da amostra) para o exame do momento de assistir televisão/ telenovela. Além do longo período de aplicação, as entrevistas em profundidade ${ }^{3}$ incorporaram 0 viés etnográfico de dar livre voz aos sujeitos da pesquisa, assumindo também a forma de longas conversas sobre temas diversos: capitais e consumo de mídia; relações de classe; relações de gênero; recepção da telenovela; trajetórias de vida na família primordial e na atual, na escola e no trabalho. 0s dados das entrevistas foram coletados entre os anos de 2012 e 2013, categorizados com 0 auxílio do software de análise qualitativa NVIV09.

As informantes, no período de coleta de dados, assistiam, majoritariamente, a novelas exibidas no horário nobre da Rede Globo de Televisão: Fina Estampa (Aguinaldo Silva; agosto de 2011 até março de 2012), Avenida Brasil (Emmanuel Carneiro; março de 2012 até outubro de 2012) e Salve Jorge (Glória Perez; outubro de 2012 até maio de 2013). Apesar das menções às telenovelas de outras emissoras, aquelas produzidas pela TV Globo continuam a ser referência crucial para a produção das representações das relações de classe e de gênero das receptoras. 0 repertório das informantes é composto da memória de novelas clássicas exibidas no horário nobre da TV Globo, além de um sem número de novelas assistidas nos demais horários e canais (SBT e Rede Record).

A primeira versão deste texto foi apresentada no GP Ficção Seriada do XV Encontro dos Grupos de Pesquisa em Comunicação, evento componente do XXXVIII Congresso Brasileiro de Ciências da Comunicação, realizado na cidade do Rio de Janeiro/RJ de 4 a 7 de setembro de 2015. Este artigo é um excerto de um projeto de pesquisa financiado pelo edital MCT/ CNPq 2012.

0 texto é parte de um projeto de investigação mais amplo, que recebeu verba do Edital Universal MCT/CNPq 14/2012.

Dentre os cinco instrumentos aplicados, caracterizamos três deles como entrevista do tipo semiestruturada (com perguntas fechadas e abertas), um como entrevista aberta e outro como entrevista biográfica, com um roteiro de questões sobre as trajetórias de vida. 


\section{Classe social, gênero e telenovelas}

A epistemologia da nossa investigação com mulheres de classe trabalhadora alinha-se aos Estudos Críticos de Recepção (Ronsini, 2014), e tem inspiração no marxismo de cunho gramsciano, na sociologia da reprodução bourdiana e em teorias de gênero, com métodos de investigação oriundos das ciências sociais. A teoria comunicacional de referência são os usos sociais de Martín-Barbero, a qual se alinha à preocupação dos Estudos Críticos de Recepção com o exame das relações sociais; entretanto, os termos não são equivalentes em função de que a abordagem dos Estudos Críticos avança no sentido de propor métodos empíricos e explicita seu compromisso com o marxismo. Na presente pesquisa, os métodos são a observação participante e o estudo de caso comparativo construído com base em perfis sociológicos individuais (Lahire, 2004), os quais reconstroem as trajetórias pessoais, familiares, escolares e profissionais das informantes.

As trajetórias nos ajudam a explicar suas disposições/inclinações de gênero em termos de um capital simbólico conformado pela condição de classe e pelas relações de classe. 0 capital simbólico não se restringe a uma autoavaliação do seu lugar no mundo (identidade pessoal), mas engloba uma feminilidade de classe que é atribuída a todas as mulheres de classe popular por uma cultura hegemônica e com a qual elas negociam modos próprios e subordinados de dar sentido à experiência.
Na categorização da feminilidade e suas relações com trajetórias femininas vividas e tipos femininos nas novelas, dedicamos particular atenção aos condicionamentos sociais do corpo. Vale dizer, os modos de posicionar o corpo, de apresentá-lo aos outros exprimem o sentido do próprio valor social da mulher na sociedade de classes (Bourdieu, 2008, p. 339-440). Pela legitimação de um estilo de vida burguês, no qual o corpo possui papel fundamental, opera-se a submissão da mulher de classes populares à violência simbólica que é sentir vergonha de si mesma (Bourdieu, 2006, p. 95).

Historicamente, as classes populares foram definidas por atributos relacionados ao corpo, por imagens de degradação, tais como contágio, promiscuidade e selvageria. Assim, a sexualidade de gênero e a degenerescência foram centrais para a classe média se afastar da aristocracia e da classe trabalhadora, exaltando a moderação sexual e econômica (Skeggs, 2004, p. 37).

A dominação masculina, que constitui as mulheres como objetos simbólicos, tem por efeito colocálas em permanente estado de insegurança corporal, ou melhor, de dependência simbólica: elas existem primeiro pela e para 0 olhar dos outros. Espera-se das mulheres que elas sejam 'femininas', ou seja, sorridentes, simpáticas, atenciosas, submissas, discretas, contidas ou até mesmo apagadas (Bourdieu, 2003, p. 82). A aprendizagem da submissão do corpo, que se dá com a cumplicidade das mulheres, é inseparável 
de uma incorporação da distinção, ou melhor, do menosprezo pela vulgaridade atribuída aos decotes muito ousados, às minissaias demasiado curtas e às maquiagens muito sobrecarregadas.

Como a telenovela ativa a correspondência entre o habitus do mundo narrado e o habitus vivido pela recepção, possibilitando o reconhecimento de si e do outro (Lopes, 2009), é pelo enfrentamento entre a trajetória da ficção e a pessoal que se firmam os sentidos de "ser mulher" dentro e fora da tela. Tal reconhecimento ocorre pelo desconhecimento dos mecanismos que conformam corpos distintos, os quais são também marcadores da posição de classe. Logo, "interessa-nos 0 estudo das distinções de classe como distinções de apropriações diferenciadas da mídia: como a mídia incide na reprodução e contestação da organização social baseada em classes sociais" (Ronsini, 2012, p.41).

As narrativas das telenovelas são produzidas com 0 intuito de expressar a distribuição social das audiências, de forma a atrair consumidores de todas as classes sociais, mesmo sendo a classe "C" a mais significativa para a indústria televisiva (Hamburger, 2005). Na construção de personagens femininas - em termos de figurino, etiqueta e comportamento -, observamos um espectro que inclui a seriedade da mulher elegante, madura ou idosa ("chique"), a irreverência da mulher jovem de classe alta, o estilo comedido da mulher de classe média e, geralmente, em tom de comicidade, o luxo da "perua" de classe alta e a hipersexualidade da periguete ${ }^{4}$.

Segundo Almeida (2013, p.115), as imagens da mulher propagadas pelas telenovelas reproduzem noções tradicionais de maternidade e amor conjugal, como a noção "moderna" da mulher que trabalha e se dedica aos cuidados do corpo e da beleza, além de administrar o espaço doméstico, sem que seja necessária a divisão de tarefas. A crítica feminista dos estudos culturais nos Estados Unidos e na Inglaterra, além da América Latina, aponta que soap operas e telenovelas não somente retratam a fragilidade feminina e sua constrição ao espaço doméstico, mas também personagens que representavam mulheres fortes, independentes, sagazes, social e economicamente poderosas (Meirelles, 2009).

Partindo do pressuposto de que disposições de gênero são indissociáveis das disposições de classe, nossa análise avança para evidenciar que a identidade feminina é produzida pela exploração econômica (no espaço doméstico e no espaço público) e pela dominação simbólica.

\section{Perfis sociológicos individuais}

Além de alguns dados demográficos das informantes (idade, ocupação, estado civil, local de residência), os retratos sociológicos incluem o capital cultural 
escolar e os desejos expressos sobre quem gostariam de ser e 0 que gostariam de aprender.

Assim como as mulheres investigadas por Almeida (2013), nove informantes aqui estudadas (Zulmira, Sara, Hilda, Eliane, Rosângela, Norma, Vilma, Jussara e Marluce) interromperam a carreira escolar para casar, cuidar dos filhos e da casa ou devido à necessidade de trabalhar para auxiliar no sustento da família. A baixa escolaridade se mostra vinculada às ocupações que exigem esforço físico, especialmente para as jovens de classe baixa e idosas de ambas as frações de classe, em que a maioria é (ou foi) empregada doméstica. Para as maduras, prevalecem as ocupações no setor dos serviços relacionados ao cuidado estético, infantil ou atendimento ao público. Apenas uma entrevistada, madura, é dona de casa. Entre todas as entrevistadas, apenas Andreia (jovem - média baixa), Eliane (madura - baixa) e Jiani (idosa - média baixa) não possuem fonte de renda própria. Andreia é estudante, Eliane, dona de casa, e Jiani parou de trabalhar. As três são sustentadas pelos maridos. Três entrevistadas, uma madura, Norma (média baixa), e duas idosas, Hilda e Sara (baixa), são as mais bem situadas economicamente em suas famílias. Além da classificação de acordo com a posição de classe e da orientação sexual heteronormativa, as informantes foram distribuídas por geração. 0 arco geracional das informantes jovens se estende dos 19 aos 24, das maduras, de 30 a 57, e das idosas, de 65 a 80.
As quatro jovens (Andreia, Luzia, Jussara e Marluce) possuem entre 19 e 24 anos de idade. Andreia e Luzia, classe média baixa, cursam, respectivamente, Direito e Publicidade e Propaganda em instituições privadas de ensino superior. Além de estudar, Luzia também é secretária. Marluce e Jussara, ambas da classe baixa, são profissionais de limpeza, doméstica e de um shopping, respectivamente. Elas também são as que menos estudaram. Marluce completou 0 Ensino Fundamental, e Jussara tem Ensino Médio incompleto. Apenas Luzia é solteira e não reside em Santa Maria. Somente Jussara possui filhos.

As maduras têm entre 30 e 57 anos de idade. Norma e Vilma, classe média baixa, têm ocupações relacionadas à estética. Norma é massoterapeuta e depiladora, Vilma, manicure e recepcionista de um hotel. Já as entrevistadas de classe baixa são Eliane, que deixou de ser empregada doméstica para se dedicar ao seu lar; e Rosângela, agricultora e auxiliar de educação infantil em uma creche. Todas são mães. Vilma e Eliane vivem em uniões estáveis. Norma e Rosângela são divorciadas, mas vivem atualmente com outros companheiros. Norma possui o Ensino Médio incompleto, e as demais entrevistadas têm Ensino Fundamental incompleto. Apenas Vilma não reside em Santa Maria/RS.

As idosas têm entre 65 e 80 anos de idade. Zulmira e Jiani pertencem à classe média baixa, e Hilda e Sara, à classe baixa. Zulmira e Hilda são aposentadas como empregadas domésticas, e 
Sara ainda se dedica à mesma profissão. Jiani era costureira autônoma. Hilda completou o Ensino Fundamental e Jiani, o Ensino Médio. Todas são mães. Zulmira e Hilda são viúvas, Jiani e Sara, casadas. Todas residem em Santa Maria/RS.

Mesmo com as diferenças de capital cultural escolarizado - que varia do Ensino Fundamental incompleto (cinco, dentre idosas e maduras), Fundamental completo (a idosa Hilda e a jovem Marluce), Médio incompleto (a madura Norma e a jovem Jussara). Médio completo (a idosa Jiani) ao Ensino Universitário incompleto (as jovens Luzia e Andreia) -, a figura feminina ideal para quase a totalidade das informantes (exceções são Luzia e Zulmira, que não citam personalidades, porém admitem admiração pelo mesmo padrão de beleza propagado na televisão) é atriz, personagem de telenovela ou celebridade midiática. As jovens elegem Flávia Alessandra e Juliana Paes; as maduras, Thais Araújo e Juliana Paes, além da figura pública da presidente Dilma Rousseff; as idosas, Hebe Camargo e as personagens "Rainha da Sucata" e "Pereirão"/Griselda. Confirma-se, assim, a centralidade do capital cultural televisivo para a conformação do habitus de gênero. 0s desejos manifestos sobre aquilo que gostariam de aprender, por seu turno, indicam a insatisfação com a subalternidade de classe oriunda de posições mal pagas e desprestigiadas socialmente: aprender a falar e a se comportar, voltar a estudar ou obter qualificação para 0 exercício de outra profissão.

\section{Definindo o que é ser mulher}

A pobreza é vista como um estado de miséria e se atribui à classe média um valor positivo, tanto econômico como moral. Evita-se o uso do termo "pobre" para falar da sua própria condição, ao invés, enfatizam-se outras carências, as culturais, consideradas como problemas individuais. À ausência de prestígio social em razão do que consideram que lhes falta, elas respondem com a valorização da solidariedade e da igualdade.

As representações sobre a condição feminina, na maior parte dos casos, estão em conformidade com a opressão de gênero, e, em menor medida, houve questionamentos sobre a desigualdade de gênero quando manifestam insatisfação acerca da sobrecarga de tarefas femininas no gerenciamento do espaço doméstico e da sua compatibilização com 0 trabalho fora do lar. A manifestação de conformidade assume a forma de uma resignação com a condição feminina e/ou a reprodução do padrão hegemônico esperado para as mulheres: a missão da maternidade, 0 embelezamento, 0 cuidado com a casa e com os membros da família, 0 trabalho fora do lar, 0 apelo à respeitabilidade moral no plano do comportamento e do exercício da sexualidade. 0 ideal feminino é a mulher capaz de dar conta de todos os aspectos da vida privada, ser reconhecida como honesta e trabalhadora, mãe e esposa exemplar.

Quando instigadas a pensar sobre os aspectos positivos e negativos da feminilidade, 
todas destacam aspectos ligados ao corpo, respectivamente, 0 prestígio da maternidade como fato biológico e o prazer extraído com as práticas de embelezamento e cuidado do corpo e 0 desconforto gerado pela natureza feminina (dores do parto, a menstruação, instabilidade emocional). 0 corpo é visto sob ataque das ocupações exercidas, as quais não permitem a manutenção de um ideal feminino de classe média: unhas feitas, cabelo escovado, maquiagem e vestuário elegante. Apenas Vilma (30) destaca o prazer sexual como positivo. A inconformidade com a desigualdade de gênero é destacada pelas jovens Jussara e Andreia, pela idosa Zulmira e pelas maduras Rosângela e Eliane.

Ao serem perguntadas sobre como uma mulher deve ser, a clivagem geracional é nítida, pois as idosas e maduras enfatizam a obrigação das mulheres em atender a todos os aspectos da vida, no trabalho, na sociedade, no lar, no cuidado com a aparência, além do valor moral da honestidade, enquanto as jovens manifestam preocupação com a moral sexual, o modo de ser (simpatia, alegria) e os cuidados de si e da aparência. 0 termo recorrente das jovens no plano da moral sexual é "se dar valor". A ideia de respeitabilidade juvenil está relacionada ao comportamento sexual considerado correto (o contrário da vulgaridade) e à aparência.

Para todas as informantes da amostra, quando comparadas aos homens, as mulheres se preocupam em resolver os problemas que envolvem a rotina doméstica, além de serem mais organizadas e ágeis na solução deles. No entanto, apesar dos reclames, nenhuma expressa o desejo de mudança do comportamento masculino, como se a maior dedicação ao lar e aos filhos fosse mesmo função delas.

Não importa a geração, as mulheres exemplares para elas são "guerreiras" e "batalhadoras", capazes de cuidar da vida privada/familiar e do trabalho, heroínas da classe popular que superam as adversidades com base na luta, predominando as figuras familiares da mãe, irmã, tia ou filha. Figuras públicas foram mencionadas por três informantes, duas maduras e uma idosa: Rosane (56) e Eliane (45), que recebem o Bolsa Família, admiram a imagem "forte" da presidente Dilma Rousseff, enquanto a informante Sara (67) menciona a atriz de telenovela Suzana Vieira. Por fim, Jiani (80) cita a figura maternal de Nossa Senhora.

Quanto ao entendimento das informantes acerca do que consideram uma mulher sensual, há uma ênfase na aparência e no comportamento considerado adequado: os cuidados com os cabelos e uso da maquiagem, com o vestuário e acessórios de modo que não sejam extravagantes, em suma, o conceito da elegância burguesa; 0 comportamento discreto que se caracteriza por modos de falar, de olhar, de sentar, etc. Entretanto, ocorrem demonstrações de rejeição ao padrão do comedimento na apresentação pessoal e/ ou do recato, posto que três mulheres (Jussara, 
23; Vilma, 30 e Zulmira, 69), mesmo que em alguns momentos das entrevistas desabonem 0 comportamento da mulher considerada vulgar, aprovam a liberdade sexual e/ou a sensualidade manifesta na aparência das periguetes. A importância do padrão de beleza é relativizada, contudo, na prática, tentam se adequar aos ditames do modelo ideal através da dieta, dos cuidados com unhas, cabelo e maquiagem; do uso do salto alto, vestuário e acessórios tidos como adequados para ocasiões especiais. A beleza é relativizada em contraposição à limpeza corporal, aos valores morais ou ao capital cultural objetivado, como fatores mais relevantes para a valorização social. Outra discussão que algumas delas levantam é a da impossibilidade de seguir 0 modelo de beleza feminino idealizado socialmente, em razão da escassez de capital econômico e da posição social, que impedem a aquisição de produtos e práticas de embelezamento e 0 tempo disponível para ser investido na aparência pessoal. Fica evidente, nas falas, a valorização da beleza sem artifícios (cirurgia plástica), "natural" ou a beleza interior, para enfrentar a vergonha por não possuírem os meios que as fariam mulheres mais valorizadas na sociedade e no espaço doméstico.

A origem da reprodução da desigualdade de gênero entre as informantes pode ser buscada na educação familiar, a qual permite a introjeção não consciente e naturalizada de determinadas disposições que conformam o habitus de gênero. Mesmo que reprovem a educação sexista que receberam - com atribuição de tarefas domésticas exclusivamente para as meninas ou com permissões para o livre exercício da sexualidade pelos filhos homens -, as entrevistadas continuam a endossar a atitude heroica da mulher "que aguenta tudo no osso do peito" (Marluce), reproduzindo as relações pouco igualitárias entre homens e mulheres nas classes populares, como enfatiza Mattos (2006). Na esfera da sexualidade, as mulheres jovens tiveram orientações para evitar a gravidez quando foram autorizadas a namorar, enquanto as idosas e maduras tiveram uma educação opressora: sem permissão para convivência com rapazes, ideais estritos de respeitabilidade moral para a mulher e liberdade sexual para os homens solteiros e casados.

A dicotomia entre corpo/emoção e alma/razão como base para a dominação de gênero não é plenamente adotada pelas mulheres da amostra, que, por um lado, vislumbram o gênero como decorrente de uma natureza corpórea e de um destino biológico e se sujeitam a administrar o espaço doméstico com pouca ou nenhuma colaboração; por outro, reconhecem-se positivamente como a alma e o corpo da casa, sendo mais capazes que os homens de controlar e racionalizar todas as tarefas, inclusive as ligadas à provisão dos recursos necessários para o sustento familiar. As mulheres, ainda que na prática continuem a reproduzir a dominação masculina, não deixam de demonstrar desconforto com a opressão de gênero, sentimento que pode ser indicativo de mudanças culturais futuras nas relações de gênero. 


\section{Definindo o que é ser mulher: o papel da telenovela}

A assistência de telenovela colabora para a construção das subjetividades e de representações acerca do valor das mulheres pertencentes às classes populares em uma disputa de sentidos entre 0 valor da feminilidade e da masculinidade nas classes sociais. A correlação entre a vida cotidiana e a ficcional se dá, em parte, pelas personagens das tramas, pois acreditamos que "a telenovela coloca modelos de comportamento por meio das personagens que apresenta, e tais personagens servem para 0 debate, a interpretação, a crítica, a projeção ou a rejeição dos públicos" (Lopes; Borelli; Resende, 2002, p.368). No percurso por entender as visões de mundo das mulheres de classes populares sobre o que significa "ser mulher", iniciamos por confrontar os modos pelos quais essas receptoras verbalizam se e como "a novela ajuda a entender a mulher" e se há identificação entre elas e alguma personagem de telenovela.

Para duas entrevistadas, Luzia (23) e Jiani (80), a telenovela, por ser texto ficcional, não auxilia na compreensão da feminilidade, tanto de modo geral quanto para refletir as mulheres que elas são. Todas as demais informantes relacionam as tramas ao entendimento sobre "ser mulher", ao aprendizado comportamental e à identificação com suas trajetórias pessoais. Para além da telenovela, Andreia (19) confirma a família e a escola como meios promotores das noções de feminilidade.

Hilda (65), Marluce (24) e Eliane (45) recorrem às dicotomias entre "bom e mau" ou "certo e errado" para expressar os exemplos que a telenovela oferta. Enquanto a jovem reforça 0 padrão hegemônico de uma mulher "forte" e "bonita", em contraposição a uma moral sexual mais liberal ("periguete"), a madura enaltece o habitus e a hexis corporal das classes elevadas, uma vez que aprende a "ter classe": "A novela mostra como é a vida real e a gente aprende como fazer certas coisas que a gente não sabia como fazer. [...] cuidar melhor de si, se vestir, saber como sentar numa mesa, como embarcar no carro, como caminhar, como ser uma mulher social, umas coisas que a gente não sabe e a gente aprende a ser uma mulher mais chique" (Eliane, 45).

Em boa parte dos relatos, a telenovela funciona como apoio às dificuldades vividas por elas mesmas, à resiliência do digno batalhador das classes populares como parte de sua jornada heroica (Escosteguy et al., 2013). É nítida a relação entre comportamentos, trajetórias e o reconhecimento de que há correspondência nos modos de ser e de viver dentro e fora da tela. Andreia e Hilda referendam Lucinda ${ }^{5}$ (Avenida Brasil, 2012) pelo cuidado com as 
crianças; Marluce fala de Pereirão/Griselda ${ }^{6}$

(Fina Estampa, 2011/2012) pela força no

trabalho e a personalidade "chorona" de

Rakelli $^{7}$ (Beleza Pura, 2008) que percebe em

si mesma. Rosângela, Sara e Vilma remetem a

personagens cujas trajetórias se assemelham às

suas, seja pela traição ou alcoolismo do marido,

pelo cuidado com os filhos, seja por enfrentar

dificuldades, ter de recomeçar e "batalhar",

valorizadas nas narrativas de Monalisa ${ }^{8}$

(Avenida Brasil, 2012), Maria do Carmo ${ }^{9}$

(Rainha da Sucata, 1990), Dona Zizi ${ }^{10}$ (Vidas

em Jogo, 2011/2012) e Aninha ${ }^{11}$ (Chocolate com

Pimenta, 2012).

Por outro lado, os dilemas da vida amorosa

e conjugal são comparados aos vividos pelas

personagens do melodrama, as quais são

modelos para questionar a autoridade masculina

e a moral sexual vigente. É assim que Rosângela
(56) e Norma (57) expõem particularidades de seus casamentos, como a traição e a opressão masculina, enquanto Zulmira (69) considera que as tramas ampliaram suas percepções sobre o que julgava errado, o que a faz romper com alguns valores e crenças passados: "eu aprendo bastante coisa... antigamente era tudo feio, e agora eu vejo outra coisa".

Jussara (22) demonstra acreditar no auxílio que a novela oferece sobre o que é ser mulher a partir da identificação com a personagem Suelen ${ }^{12}$ (Avenida Brasil, 2012), que se dá pelo comportamento amoroso e sexual mais liberto: "Porque algumas a gente se identifica. [...] A Suelen. Ela gostava de jogar futebol, andava com um e com outro. Saía, e acabou ficando com dois. Ela tinha tudo que ela queria". Quando questionada, justifica: "Porque ela é que nem eu, divertida e gostosona". Vilma também revela apreciar a "estética periguete",

Interpretada por Lília Cabral, trabalhava com pequenos consertos para sustentar a família. Seu figurino operário, macacão, boné e ferramentas, reforçava o imaginário de "marido de aluguel" ou "faz tudo" e de uma mulher distante da vaidade. Ganha na loteria e ascende socialmente.

Interpretada por Isis Valverde, a jovem manicure trabalhava no salão de beleza de sua mãe. Seu sonho era ser dançarina de um programa de televisão.

A paraibana, interpretada por Heloísa Périssé, foi, ainda jovem, para o Rio de Janeiro em busca de oportunidades. Torna-se sócia de um salão de beleza, o qual garante, com o passar dos anos, bom retorno financeiro a ela e ao filho adotivo que criou sozinha.

Regina Duarte interpreta uma moça que ascende após fazer fortuna junto com o pai a partir de um ferro-velho. Como empresária bem-sucedida, ganha 0 apelido de "Rainha da Sucata".

10 A doceira vivida por Lucinha Lins sustenta 0 lar, já que o marido está desempregado. Encontra a filha às escondidas, pois 0 marido expulsou a filha de casa por não aceitar seu trabalho de dançarina.

11 Mariana Ximenes dá vida à personagem brejeira que trabalhava como faxineira em uma fábrica de chocolates. Grávida de um rapaz, é ajudada pelo dono da fábrica de chocolates, que se casa com ela e assume a paternidade do filho. Vão morar em Buenos Aires, onde ela recebe aulas de etiqueta e retorna, anos depois, à cidade como uma mulher elegante.

12 Interpretada por Isis Valverde, Suelen, uma jovem de classe popular, era chamada de periguete por utilizar roupas curtas e/ ou justas e por envolver-se frequentemente com diferentes parceiros sexuais. 
uma vez que aprova 0 aspecto físico e 0 figurino de Teodora ${ }^{13}$ (Fina Estampa, 2011/2012): "Adorava ver ela, toda chique com aquelas roupas bem curtinhas... loiraça. [...] Eu achava bonita, não que eu me pareça com ela. Mas achava bonito 0 jeito que ela se vestia...”. A noção da identificação, nesses dois casos, remete à beleza corporal e à sensualidade da "periguete", estando também vinculada à liberdade sexual feminina, enquanto a idosa Zulmira, além de projetar na personagem Suelen o ideal do corpo juvenil que permitiria a ascensão social às mulheres das classes populares, também aprova a liberdade sexual manifesta pela personagem. As personagens de extração humilde são categorizadas como boas mães, fortes, guerreiras e batalhadoras, tais como Lucinda (Avenida Brasil, 2012), Penha ${ }^{14}$ (Cheias de Charme, 2012) ou Griselda (Fina Estampa, 2011/2012). A maldade das mulheres de classe alta ou vulgaridade manifesta por mulheres da elite ou das classes populares é reprovada. 0s temas que lhes chamam a atenção são o tráfico de mulheres na novela Salve Jorge, o desvio de dinheiro em Avenida Brasil e a arrogância ou crueldade (Tereza Cristina, Fina Estampa; Carminha, Avenida Brasil; Chayene, Cheias de Charme). A vulgaridade é característica da "periguete" de classe popular (Suelen, Avenida Brasil) e das mulheres de classe alta que disputam um mesmo homem (Verônica, Noêmia e Aléxia, Avenida Brasil) ou traem o marido (Carminha, Avenida Brasil).

A distinção nos modos de ser entre as classes é reforçada quando as entrevistadas são interpeladas a descrever o percurso de personagens de classes altas e populares. Prevalecem, entre as personagens associadas às classes populares, aquelas cujas trajetórias são de ascensão social por intermédio do trabalho, do esforço e do casamento, e cujo caráter permanece inalterado. Com relação às personagens de classe alta, há uma preferência pelas personagens que representam vilãs e que, normalmente, são descritas como pouco apegadas à família, ao trabalho e aos cuidados domésticos - o que evidencia, mais uma vez, a percepção de que essas são "boas qualidades" de uma mulher. Fica claro, por outro lado, que os principais atributos positivos considerados dizem respeito à forma de vestir das personagens de classe alta.

As falas remetem, em sua maioria, a um padrão "chique" (associado ao salto alto, ao terninho ou ao comportamento), mas também podem servir para "depreciar" uma personagem má e afortunada em razão das roupas "sempre justas"

13 Carolina Dieckmann interpreta uma jovem ambiciosa que abandona o marido e o filho para tentar a sorte nos Estados Unidos ao lado de um lutador de vale-tudo. Retorna ao Brasil e se aproxima da família quando descobre que a sogra Griselda ganhou na loteria.

14 Taís Araújo dá vida a uma empregada doméstica que sustenta o marido, o filho e dois irmãos. Une-se a duas outras empregadas domésticas e forma o grupo musical Empreguetes, tornando-se famosa. 
de Tereza Cristina ${ }^{15}$, da vulgaridade de Carminha ${ }^{16}$, da demonstração do capital cultural não condizente com a posição social da personagem Ivana ${ }^{17}$ (Avenida Brasil, 2012), desabonada por "não saber se vestir", não falar direito e ser "brega". A escolha dessas personagens de classe alta revela o modo pelo qual as apropriações da telenovela pelas receptoras reproduzem 0 habitus desta classe. 0 padrão esperado para a classe alta é o da elegância no comportamento e no vestuário, bem como o do comedimento sexual. Em Fina Estampa, Tereza Cristina não se encaixa no habitus de sua classe, pelo vestuário provocante e pelo envolvimento com Pereirinha, o pescador. Em contrapartida, Griselda, mesmo com mobilidade social ascendente, permanece "simples", e a histeresis do habitus, retratada com realismo pela ficção, é aprovada pelas receptoras que consideram Griselda uma mulher de classe popular. Carminha (Avenida Brasil) não apresenta as virtudes das classes menos abastadas depois de ter subido na vida, e Ivana, da mesma novela, mantém seu habitus de classe popular e é criticada por não incorporar a hexis corporal das elites (Bourdieu, 2008).
Tanto as entrevistadas que valorizaram a ascensão social de personagens de classes populares quanto as que observam a inadequação do habitus de gênero ou do capital cultural de personagens com capital econômico alto reivindicam a manutenção de características consideradas como positivas para a classe popular ascendente - simplicidade, humildade, caráter - e a transformação de aspectos corpóreos do habitus - a hexis e o vestuário - , em que as personagens devem abandonar roupas, gestos e tom de voz não condizentes com a discrição burguesa. Tais observações corroboram os achados de Almeida (2001), em que as receptoras da telenovela $O$ Rei do Gado (Rede Globo, 1996) rejeitaram a mocinha Luana por não conseguir se desvincular do seu habitus de agricultora sem-terra, mesmo quando casou com um homem muito rico.

A noção do conservadorismo, para dez das doze informantes, é uma característica comum às mulheres virtuosas. Estas, que são sérias, discretas e dedicadas ao trabalho e à família, qualidades que são percebidas pelas receptoras nas personagens Monalisa e Janaína ${ }^{18}$ (Avenida

15 Christiane Torloni vive uma socialite preocupada em manter o nome da família, embora viva em conflito com os filhos e 0 marido. Maltrata os empregados.

16 Interpretada por Adriana Esteves, é a vilã da trama. Fria e ambiciosa, casou-se com um jogador de futebol e o traiu por anos com seu cúmplice de golpes, Max (Marcello Novaes).

17 Letícia Isnard vive a sócia de Monalisa (Heloísa Périssé) em um salão de beleza. É cunhada de Carminha (Adriana Esteves) e casada com Max (Marcello Novaes), que a maltrata, pois se casou por interesse, a mando de sua amante e cúmplice, Carminha.

18 Claudia Missura vive uma das empregadas domésticas de Tufão (Murilo Benício) e Carminha (Adriana Esteves). Mãe solteira, sustenta o filho, que acaba se envolvendo em crimes. 
Brasil), Griselda (Fina Estampa), Celina ${ }^{19}$

(Chocolate com Pimenta), Dona Zizi (Vidas em

Jogo), Edilásia Sardinha ${ }^{20}$ (Da Cor do Pecado).

A mulher conservadora é aquela que preza pelo núcleo familiar, enfrenta dificuldades para mantêlo coeso, trabalha e mantém uma moral sexual, mesmo quando solteira. Apenas a idosa Zulmira é crítica a uma moral bastante rígida: é "aquela que acha tudo feio, não é isso? [...], e deus 0 livre isso, deus o livre aquilo". A representação da mulher liberal na telenovela está associada, para oito informantes, ao comportamento vulgar, àquela que "não se preserva" ou é infiel. As personagens citadas se envolvem com vários homens (Bebel, Paraíso Tropical; Carminha, Avenida Brasil; Norminha, Caminho das Índias; Suelen, Avenida Brasil). Zulmira, novamente, é a única entrevistada da amostra que percebe na mulher liberal aspectos positivos relacionados à sexualidade e exposição do corpo: "Ah... a Suelen é liberal. Eu achava que é né, é o que faz o que quer. [...] eu não tenho corpo bonito, mas eu acho bem legal, eu também posaria nua se tivesse um corpo, pra ganhar dinheiro".

Em síntese, o julgamento sobre o modo de ser das personagens de classe alta diz respeito à questão moral ligada a um habitus de gênero, ou seja, elas não exercem bem o papel feminino esperado na família e na vida amorosa; tampouco desempenham as práticas relacionadas ao habitus de classe dominante. As personagens de classe popular são majoritariamente aprovadas quando encarnam os valores da respeitabilidade e da dignidade no trabalho e na vida íntima. As exceções à regra das três gerações estudadas - Zulmira, Vilma e Jussara - revelam a contestação dos padrões hegemônicos de classe e de gênero em operação: a subalternidade que teima em se opor, mesmo quando associada à representação da vulgaridade.

\section{Conclusões}

As telenovelas - aqui examinadas sob o ponto de vista das receptoras e não a partir de uma análise textual, narrativa ou discursiva - oferecem às mulheres das classes populares promessas de transformação da vida amorosa, padrões de comportamento sexual, modos (respeitáveis) de apresentação no espaço público e o modelo do self ideal burguês. 0 princípio sexista da vida privada como responsabilidade feminina e da vida pública como esfera masculina é vivido pelas informantes e, parcialmente, reforçado pela incorporação do modelo da mulher "batalhadora" das heroínas do melodrama.

Quando comparadas às experiências das informantes no casamento e namoro, as relações

19 Samara Felippo interpreta uma moça virtuosa e é obrigada a se casar com um banqueiro para proteger a família. Envolve-se em trapalhadas para evitar um relacionamento físico com o marido.

20 Rosi Campos interpreta a matriarca de uma família de lutadores no Rio de Janeiro. Viúva, vende sanduíches naturais e sucos no seu quiosque na praia para sustentar seus cinco filhos. 
entre casais nas tramas são mais igualitárias e podem ter sido apropriadas como modelos de relacionamentos satisfatórios para as mulheres que se casaram pela segunda vez. Semelhante ao que foi demonstrado sobre o impacto da novela e seus núcleos familiares pequenos (junto com outros fatores, como a adoção massiva de métodos contraceptivos e a melhora do nível educacional das jovens) para a queda de natalidade no Brasil desde a década de 1960 (Gorney,2011; La Ferrara, Chong, Duryea, 2012).

Os padrões de comportamento sexual aceitos incluem a monogamia sucessiva, quando a relação afetiva no casamento ou namoro é considerada problemática, podendo-se inferir que a apropriação das novelas enseja tanto o exercício de maior liberdade sexual para as mulheres, quanto os reclames relativos às permissões concedidas ao homem para a prática de relacionamentos sexuais eventuais.

0 exame da recepção das telenovelas nos revela a luta de classes no campo dos valores morais, na qual as vilãs das classes dominantes se contrapõem às heroínas das classes trabalhadoras. As primeiras são admiradas pela elegância e pelo bem vestir; as segundas, pelas virtudes morais que não dependem do capital econômico. Nesta articulação se reproduz a distinção de classe, tendo em vista que o estilo de vida burguês - conformado pelos capitais econômico, social, cultural e simbólico - é legitimado, restando aos humildes as virtudes morais. Neste sentido, o exame da recepção revelou os usos (sociais) das telenovelas através da incorporação de um padrão heteronormativo dominante de relações de gênero que é determinado pela posição de classe.

\section{Referências}

ALMEIDA, H. B. "Muitas mais coisas": telenovela, consumo e gênero. 320 f. Tese (Doutorado em Ciências Sociais) - Universidade Estadual de Campinas, Campinas, 2001.

. As mulheres e as imagens da televisão. In:

VENTURI, Gustavo; GODINHO, Tatau (orgs.). Mulheres brasileiras e gênero nos espaços público e privado: uma década de mudanças na opinião pública. São Paulo: Editora Fundação Perseu Abramo, 2013. BOURDIEU, P. A dominação masculina. Rio de Janeiro: Bertrand Brasil, 2003. A odisséia da reapropriação: a obra de Mouloud Mammeri. Revista de Sociologia e Política, Curitiba, n. 26, p. 93-95, jun. 2006.

. A distinção: crítica social do julgamento. São Paulo: Edusp; Porto Alegre: Zouk, 2008.

ESCOSTEGUY, A. C. et al. História de mulheres: heroínas de uma narrativa melodramática. Intexto, Porto Alegre, n. 28, p. 100-117, 2013.

GORNEY, Cynthia. Brazil's Girl Power. [S.I.]: National Geographic, set. 2011. Disponível em: < http://ngm. nationalgeographic.com/2011/09/girl-power/gorneytext>. Acesso em 10 de maio de 2016.

HAMBURGER, E. 0 Brasil antenado: a sociedade da novela. Rio de Janeiro: Jorge Zahar, 2005.

LA FERRARA, E.; CHONG, A.; DUREYA, S. Soap operas and fertility: evidence from Brazil. American Economic Journal: Applied Economics. v. 4, n. 4, p. 1-31, out. 2012. 
LAHIRE, B. Retratos sociológicos: disposições e variações individuais. Porto Alegre: Artmed, 2004.

LOPES, M. I. V. Telenovela como recurso comunicativo.

Matrizes, São Paulo, v. 3, n. 1, p. 21-47, 2009.

LOPES, M. I. V.; BORELLI, S. H. S.; RESENDE, V. R.

Vivendo com a telenovela: mediações, recepção, teleficcionalidade. São Paulo: Summus, 2002.

MARTÍN-BARBER0, J. Uma aventura epistemológica. Matrizes, São Paulo, v. 2, n. 2, p. 143-162, 2009.

MATTOS, Patrícia. A mulher moderna numa sociedade desigual. In: SOUZA, Jessé (org.). A invisibilidade da desigualdade brasileira. Belo Horizonte: Editora UFMG, 2006, p. 153-195.

MEIRELLES, Clara Fernandes. Prazer e resistência: A legitimação do melodrama nos contextos acadêmicos. 212 f. Dissertação (Mestrado em Comunicação e Cultura). Universidade Federal do Rio de Janeiro, Rio de Janeiro, 2009.

RONSINI, V. M. A crença no mérito e a desigualdade: a recepção da telenovela no horário nobre. Porto Alegre: Sulina, 2012.

. El polvo de la tradición en la carretera de los Estudios Culturales. In: MALDONADO, Alberto E. (coord.). Panorâmica da investigação em comunicação no Brasil. Salamanca: Comunicación Social, 2014, p.75-98.

SKEGGS, B. Class, self and culture. London: Routledge, 2004. 


\section{Expediente}

A revista E-Compós é a publicação científica em formato eletrônico da Associação Nacional dos Programas de Pós-Graduação em Comunicação (Compós). Lançada em 2004, tem como principal finalidade difundir a produção acadêmica de pesquisadores da área de Comunicação, inseridos em instituições do Brasil e do exterior.

\section{E-COMPÓS I www.e-compos.org.br I E-ISSN 1808-2599}

Revista da Associação Nacional dos Programas de Pós-Graduação em Comunicação.

Brasília, v.20, n.1, jan./abr. 2017.

A identificação das edições, a partir de 2008, passa a ser volume anual com três números.

Indexada por Latindex I www.latindex.unam.mx

\section{CONSELHO EDITORIAL}

Alda Cristina Silva da Costa, Universidade Federal do Pará, Brasil Alfredo Luiz Paes de Oliveira Suppia, Universidade Estadual de Campinas, Brasil Álvaro Larangeira, Universidade Tuiuti do Paraná, Brasil Ana Carolina D. Escosteguy, Pontifícia Universidade Católica do Rio Grande do Sul, Brasil Ana Regina Barros Rego Leal, Universidade Federal do Piauí, Brasil Ana Carolina Rocha Pessôa Temer, Universidade Federal de Goiás, Brasil Andrea França, Pontifícia Universidade Católica do Rio de Janeiro, Brasil André Luiz Martins Lemos, Universidade Federal da Bahia, Brasil Angela Cristina Salgueiro Marques, Faculdade Cásper Libero, Brasil Ângela Freire Prysthon, Universidade Federal de Pernambuco, Brasil Antonio Carlos Hohlfeldt, Pontifícia Universidade Católica do Rio Grande do Sul, Brasil Arthur Ituassu, Pontifícia Universidade Católica do Rio de Janeiro, Brasil Bruno Campanella, Universidade Federal Fluminense, Brasil Cláudio Novaes Pinto Coelho, Faculdade Cásper Líbero, Brasil Carlos Eduardo Franciscato, Universidade Federal de Sergipe, Brasil Denise Tavares da Silva, Universidade Federal Fluminense, Brasil Eduardo Vicente, Universidade de São Paulo, Brasil Eliza Bachega Casadei, Escola Superior de Propaganda e Marketing - SP, Brasil Elizabeth Nicolau Saad Corrêa, Universidade de São Paulo, Brasil Erick Felinto de Oliveira, Universidade do Estado do Rio de Janeiro, Brasil Erly Vieira Júnior, Universidade Federal do Espirito Santo, Brasil Francisco de Assis, FIAM-FAAM Centro Universitário, Brasil Francisco Elinaldo Teixeira, Universidade Estadual de Campinas, Brasil Frederico de Mello Brandão Tavares, Universidade Federal de Ouro Preto, Brasil Gabriela Reinaldo, Universidade Federal do Ceará, Brasil Gilson Vieira Monteiro, Universidade Federal do Amazonas, Brasil Gustavo Daudt Fischer, Universidade do Vale do Rio dos Sinos, Brasil Igor Sacramento, Fundação Oswaldo Cruz, Brasil Itania Maria Mota Gomes, Universidade Federal da Bahia, Brasil Jiani Adriana Bonin, Universidade do Vale do Rio dos Sinos, Brasil José Afonso da Silva Junior, Universidade Federal de Pernambuco, Brasil
José Luiz Aidar Prado, Pontifícia Universidade Católica de São Paulo, Brasil Juçara Gorski Brittes, Universidade Federal de Ouro Preto, Brasil Laura Loguercio Cánepa, Universidade Anhembi Morumbi, Brasil Liziane Soares Guazina, Universidade de Brasilia, Brasil Luíza Mônica Assis da Silva, Universidade Católica de Brasília, Brasil Maria Ataide Malcher, Universidade Federal do Pará, Brasil Maria Elisabete Antonioli, Escola Superior de Propaganda e Marketing - SP, Brasil Maria das Graças Pinto Coelho, Universidade Federal do Rio Grande do Norte, Brasil Marcel Vieira Barreto Silva, Universidade Federal da Paraíba, Brasil Marcia Tondato, Escola Superior de Propaganda e Marketing, Brasil Marli Santos, Universidade Metodista de São Paulo, Brasil Márcio Souza Gonçalves, Universidade do Estado do Rio de Janeiro, Brasil Mauricio Mario Monteiro, Universidade Anhembi Morumbi, Brasil Mauricio Ribeiro da Silva, Universidade Paulista, Brasil Mauro de Souza Ventura, Universidade Estadual Paulista, Brasil Mayka Castellano, Universidade Federal Fluminense, Brasil Micael Maiolino Herschmann, Universidade Federal do Rio de Janeiro, Brasil Mozahir Salomão Bruck, Pontifícia Universidade Católica de Minas Gerais, Brasil Nísia Martins Rosario, Universidade Federal do Rio Grande do Sul, Brasil Potiguara Mendes Silveira Jr, Universidade Federal de Juiz de Fora, Brasil Raquel Ritter Longhi, Universidade Federal de Santa Catarina, Brasil Regiane Regina Ribeiro, Universidade Federal do Paraná, Brasil Roberto Elísio dos Santos, Universidade Municipal de São Caetano do Sul, Brasil Rodolfo Rorato Londero, Universidade Estadual de Londrina, Brasil Sérgio Luiz Gadini, Universidade Estadual de Ponta Grossa, Brasil Simone Maria Andrade Pereira de Sá, Universidade Federal Fluminense, Brasil Simone Maria Rocha, Universidade Federal de Minas Gerais, Brasil Suzana Reck Miranda, Universidade Federal de São Carlos, Brasil Tarcyanie Cajueiro Santos, Universidade de Sorocaba, Brasil Tatiana Oliveira Siciliano, Pontifícia Universidade Católica do Rio de Janeiro, Brasil Veneza Mayora Ronsini, Universidade Federal de Santa Maria, Brasil

\section{CONSELHO CIENTÍFICO}

Cristiane Freitas Gutfreind, Pontifícia Universidade Católica do Rio Grande do Sul, Brasil Eduardo Morettin, Universidade de São Paulo, Brasil

Felipe Costa Trotta, Universidade Federal Fluminense, Brasil Irene de Araújo Machado, Universidade de São Paulo, Brasil

\section{COMISSÃO EDITORIAL}

Eduardo Antonio de Jesus, Universidade Federal de Minas Gerais, Brasil Marco Antonio Roxo da Silva, Universidade Federal Fluminense, Brasil Osmar Gonçalves dos Reis Filho, Universidade Federal do Ceará, Brasil

\section{CONSULTORES AD HOC}

Kelly C. de Souza Prudencio, Universidade Federal do Paraná, Brasil Francisco P. Jamil A. Marques, Universidade Federal do Paraná, Brasil Tiago Quiroga F. Neto, Universidade de Brasília, Brasil

\section{EQUIPE TÉCNICA}

ASSISTENTE EDITORIAL Márcio Zanetti Negrini REVISÃO DE TEXTOS Press Revisão EDITORAÇÃO ELETRÔNICA Roka Estúdio IMAGEM DE CAPA Silas de Paula

\section{COMPÓS I www.compos.org.br}

Associação Nacional dos Programas de Pós-Graduação em Comunicação

Presidente

Edson Fernando Dalmonte

Programa de Pós-Graduação em Comunicação

e Cultura Contemporânea - UFBA

edsondalmonte@uol.com.br

Vice-presidente

Cristiane Freitas Gutfreind

Programa de Pós-Graduação em Comunicação Social - PUC-RS cristianefreitas@pucrs.br

Secretário-Geral

Rogério Ferraraz

Programa de Pós-Graduação em Comunicação

Universidade Anhembi Morumbi

rogerioferraraz@anhembimorumbi.edu.br

CONTATO I revistaecompos@gmail.com 